\title{
The opportunity to create a business: Systemic banking crisis, institutional factor conditions and trade openness
}

\author{
José Carlos Pinho ${ }^{1}$ (D) Maria de Lurdes Martins ${ }^{1}$ \\ Published online: 30 May 2020 \\ (C) Springer Science+Business Media, LLC, part of Springer Nature 2020
}

\begin{abstract}
This study examines the impact of several institutional factor conditions on entrepreneurship in difficult macroeconomic environments such as a systemic banking crisis. It uses data from the National Expert Survey (NES-GEM). A total of 1771 national entrepreneurship experts representing 44 countries were included in the analysis. Using Laeven and Valencia (2013)'s criteria, 20 countries were considered as most affected by the global economic crisis (group 1) and 24 as less affected (included in group 2) in order to test if opportunity perceptions are significantly affected in times of recovery. In terms of findings, the study confirms that institutional factor conditions strongly impact on the opportunity to create a new business regardless of how damaged the economy of countries hit by the crisis was. Among the six institutional factors studied, four are found to be statistically significant and two are partially significant. The interacting effects of systemic banking crisis and the exposure to international conditions kept the previous relationship relatively unchanged. In terms of contributions, the study first highlights the importance of the institutional view in explaining the opportunities to start-up in the aftermath of a crisis. Second, the study compares the proposed relationships between four sub-sample data sets based on trade openness and banking crisis severity. From a practical and government perspective, this study provides a useful picture of the yet limited understanding of the role that institutions and trade openness can play in entrepreneurs' perceptions and thus in economic recovery dynamics.
\end{abstract}

José Carlos Pinho

jcpinho@eeg.uminho.pt

Maria de Lurdes Martins

lmartins@eeg.uminho.pt

1 School of Business and Management, University of Minho-Campus de Gualtar, 4710-057 Braga, Portugal 


\section{Resumen}

Este estudio examina el impacto de varias condiciones de carácter institucional en el emprendimiento en ambientes macroeconomicamente adversos, tales como durante una crisis bancaria sistémica. Para ello, utiliza datos de la Encuesta Nacional de Expertos (NESGEM). En representación de 44 países, un total de 1771 expertos en emprendimiento nacional fueron seleccionados para ser incluidos en el análisis. Usando los criterios de Laeven y Valencia (2013), 20 países fueron considerados como los más afectados por la crisis económica mundial (Grupo 1) y 24 como los menos afectados (incluidos en el grupo 2) para analisar si, en tiempos de recuperación, la percepción de oportunidades es afectada significativamente. Respecto a los resultados, el estudio confirma que las condiciones institucionales tienen un fuerte impacto en la oportunidad de crear un nuevo negocio, independientemente de cuán afectada estuviese la economía de los países trastocados por la crisis. De los seis factores institucionales estudiados, cuatro fueron estadísticamente significativos y dos parcialmente significativos. Los efectos de interacción entre la crisis bancaria sistémica y la exposición a condiciones internacionales mantuvieron la relación relativamanete sin alteraciones. Respecto a las contribuciones, el estudio destaca, en primer lugar, la importancia de la visión institucional en la explicación de las posibilidades de crear un nuevo negocio después de una crisis. En segundo lugar, el estudio compara las relaciones propuestas entre cuatro conjuntos de datos de submuestras basados en la apertura comercial y la severidad de la crisis bancaria. Desde una perspectiva práctica y de gobierno, este estudio ofrece un útil retrato del limitado conocimiento que existe respecto al rol que desempeñan tanto las instituciones como la apertura comercial en la percepción de los emprendedores $\mathrm{y}$, por lo tanto, en la dinámica de recuperación económica.

Keywords Institutional theory · Systemic banking crisis · Entrepreneurial opportunities · Institutional factor conditions $\cdot$ Trade openness

\section{Summary highlights}

Research Questions/Purpose: The main purpose of the study is to investigate the importance of several institutional factor conditions and trade openness on the perception of an opportunity to create a business during a systematic banking crisis.

Justification and contributions of the research: This study contributes to the literature by extending what we already know about the role of several institutional factor conditions and trade openness on the perception of an opportunity to create a business during a systematic banking crisis. It also builds on the institutional theory, which relies on three institutional pillars (normative, regulatory, and cultural-cognitive).

Methods: Relying on a global survey, this study uses data from National Expert Survey (NES)-Global Entrepreneurship Monitor.

Information/Data: Data were collected through the application of a questionnaire to National Experts in a cross-cultural context. A total of 1771 National Entrepreneurship Experts representing 44 countries were selected to be included in the analysis. 
Results/findings: This study confirms that institutional factor conditions strongly impact on the opportunity to create a new business regardless of how damaged the economy of countries hit by the crisis was. Among the six institutional factors studied, four are found to be statistically significant and two are partially significant. The interacting effects of systemic banking crisis and the exposure to international conditions kept the previous relationship relatively unchanged.

Limitations: This study is limited by the fact that each sub-sample only covers 1 year. In addition, the institutional factor conditions (or framework) are assessed in the form of national experts' perceptions rather than objective reality per se.

Theoretical Implications and Recommendations: A relevant theoretical implication derived from the present study relates to the fact that the effect of all studied institutional factor conditions on the opportunity to create a business does not differ significantly for the two sub-samples (systemic non-banking crisis vs. banking crisis countries).

Practical and Managerial Implications and Recommendations: This study is useful for designing a supportive institutional background that fosters the creation of a set of opportunities to create a business within an adverse context.

Policy Implications and Recommendations: Our findings suggest that institutional factor conditions may have an important role in improving governments' policies and reactions to global crisis (economic recession, natural disaster, global health pandemic, etc.).

\section{Introduction}

Assuming that entrepreneurial activity is crucial for economic growth, development, employment, and innovation (Simón-Moya et al. 2016), the systemic banking crisis that ocurred before 2012 may have brought about important changes in the perception of opportunities for the creation of a new business, slowing down the recovery processes, despite all measures and policies taken by public authorities. To enrich our understanding of this phenomenon, this study also assumes that economies that are more exposed to international conditions, e.g., economies that evidence a considerable dependency on international trade, may be more affected by the above mentioned changes.

The more recent systemic banking crisis, which has also been labeled as a "global financial crisis", started in the major US financial institutions and spread throughout the global economy, particularly to Europe, causing severe social, political, and economic consequences. This global crisis, which was strongly associated with a systemic banking crisis, disrupted the toughness of the European economy leading to the economic disequilibrium of countries known as PIIGS (Portugal, Italy, Ireland, Greece, and Spain) as was reflected in the rating agencies that increased the sovereign risk rates, causing a weakness of the Euro (Reyes and Moslares 2010). In line with Giotopoulos et al. (2017), this global financial crisis whose origin is associated with a systemic banking crisis was considered one of the most severe crisis in the last decades effecting not only a significant drop in demand for products and services but also having severe implications on credit crunch conditions. As a result, conditions were adverse in terms of opportunities to create a new 
business. If governments react to boost growth by stimulating the opportunities perceived by managers, then the negative impact of the crisis can be counterbalanced by strong institutional factor conditions, such as cultural and social norms that encourage entrepreneurship, internal market openness, entrepreneurial education, government programs, among others, even when countries are more negatively affected by unanticipated changes in economic conditions. Ultimately, several authors stressed "how" entrepreneurs are guided and influenced by the surrounding environment or institutional context (Arabiyat et al. 2019; Bruton et al. 2010; Busenitz et al. 2000; Urbano and Alvarez 2014; Raza et al. 2019, among others).

Unlike previous crises, the systemic banking crisis affected mostly advanced economies as can be confirmed using the database of Laeven and Valencia (2013) (which was followed in this study to distinguish the most affected countries from the others, a list with both groups of countries is found in Table 1). These economies, however, have more space to implement counter-cyclical policy responses which can easily foster other factors that can minimize the negative consequence of the crisis. This study posits that this systemic banking crisis caused serious implications for new and growing businesses and cutting down on costs was a common reaction of most small firms. This crisis was directly associated with the drying up of credit from the banking system due to the increase in customer defaults (Papaoikonomon et al. 2012; Simón-Moya et al. 2016). However, periods of economic adjustments are also a good opportunity for current entrepreneurial firms to reorganize and rethink the economic viability of their business cutting certain fixed costs and mainly to undertake new investments in high-potential growth areas. It is generally recognized that behind a crisis, there are a large amount of opportunities (some of them are government-driven). In line with Bosma et al. (2018), institutions have a crucial impact on the prevalence and nature of entrepreneurship. These may act, as they noted, as conduits of entrepreneurial talent towards productive entrepreneurship. Therefore, the institutional environment in which new business takes place assumes particular relevance as it defines, creates, and limits entrepreneurial opportunities and most important may affect entrepreneurial growth rates (Urbano and Alvarez 2014). Aparicio et al. (2016) studied the institutional factors that stimulate opportunity entrepreneurship and subsequently explain economic growth.

The understanding of the institutional factors that determine the opportunity to create a new business is of crucial importance (Stenholm et al. 2013). Baumol (1990) argued that understanding the institutional factors that shape entrepreneurial opportunities is relevant as it allows for an efficient allocation of resources. Previous research has also emphasized the increasing importance of the institutional framework in which the individual is embedded (North 1990). Other studies draw a distinction between managerial and entrepreneurial economies, to identify groups of countries with similar entrepreneurial activity and economic variables as well as determining the institutional drivers for each group (Abdesselam et al. 2017). As these authors acknowledged, the financial crisis involved a break in entrepreneurial dynamism, with agricultural economies resisting the financial crisis better. Still, others considered the impact of a prolonged economic recession on the entrepreneurial intentions of young people, distinguishing between propensity to start a new business and perceived likelihood of becoming an entrepreneur (Arrighetti et al. 2016). In a recent study, Ali and Muffatto (2019) conducted a rigorous systematic review of 17 years of literature in order to identify studies that have empirically explored the effect of three formal institutions on cross-country entrepreneurial attitudes. 
Table 1 The two groups: banking crisis countries (20) and the other countries (24) in the sample

\begin{tabular}{llll}
\hline \multicolumn{2}{l}{ Banking crisis countries } & \multicolumn{2}{l}{ Other countries in the sample (24 countries) } \\
\hline Austria [37](17) & Netherlands [37](14) & Argentina [37](21) & Japan [36](32) \\
Belgium [53](28) & Nigeria [36](18) & Brazil [87](39) & Korea, Rep. [54](48) \\
Denmark [31](15) & Portugal [36](25) & China [37](33) & Malaysia [36](26) \\
France [37](13) & Russia [36](20) & Colombia [50](24) & Mexico [36](29) \\
Germany [60](21) & Slovenia [36](29) & Costa Rica [36](18) & Namibia [36](18) \\
Greece [36](15) & Spain [39](16) & Croatia [45](34) & Panama [36](23) \\
Hungary [36](20) & Sweden [36](12) & Ecuador [36](24) & Peru [42](28) \\
Ireland [38](18) & Switzerland [36](18) & Egypt [36](23) & Singapore [36](21) \\
Italy [38](24) & United Kingdom [36](13) & Estonia [41](12) & South Africa [37](22) \\
Latvia [36](21) & United States [36](16) & Finland [36](23) & Thailand [36](35) \\
& & India [72](43) & Turkey [37](21) \\
& & Israel [34](10) & Uruguay [36](18) \\
\hline
\end{tabular}

Notes: number of respondents in parenthesis. Total sample: 1771 observations, of which 766 are representative of countries affected by banking crisis and 1005 are representative of the remaining countries The second number in each cell represents the number of observations per country after removing missing values (total of 998 observations, of which 373 are representative of banking crisis countries and 625 are representative of other countries. Two groups based on Laeven and Valencia (2013)'s IMF paper

In turn, Williams and Vorley (2015) undertook a somewhat different view and showed that some formal institutional changes imposed by EU on Greece during the global financial crisis caused limited entrepreneurial opportunities.

This is also in line with Stenholm et al. (2013) who stated that there is scant literature on how certain supportive or conductive aspects in the national environment have affected entrepreneurial activity. Similarly, Riaz (2009) maintained that the institutional theory may help to "understand the complexities of organizational-institutional interplay in contexts such as the present crisis" (Riaz 2009, p. 28). In fact, countries facing budget deficit problems under intervention by international entities, such as the IMF and the European Central Bank, are vested with considerable authority and legitimacy to tackle market failures and control the deficit. Considering the previous studies, we may conclude that little attention has been directed at understanding how several institutional factor conditions, viewed by national entrepreneurship experts, impact on the opportunity to create a business, particularly in a global economic crisis context. Hence, to the best of our knowledge, our study is different from the previous ones as it examines the impact of several institutional factor conditions and trade openness on the perception of an opportunity to create a business during a systematic banking crisis, thereby it fullfills an important gap in the literature.

To achieve this goal, this study uses the lens of the institutional theory (Scott 1995) which relies on three major institutional pillars (normative, regulatory, and culturalcognitive). In a recent study, Urbano et al. (2019) carried out a systematic literature analysis over the last 25 years of research on institutions, entrepreneurship, and economic growth and found that a number of scholars have used Scott's (2014) institutional dimensions or pillars (Busenitz et al. 2000; Kostova 1997; Arabiyat et al. 2019; among others). In a sense, this study advances knowledge in a related field as it assumes that the three Scott institutional pillars influence entrepreneurial 
opportunities. Although this study posits that the country's macroeconomic stability, and subsequently a stable institutional framework are necessary conditions for the good functioning of the business environment, the global financial crisis may produce an important effect on perceived entrepreneurial opportunities. It is equally expected that this interaction effect is perceived differently by national experts in entrepreneurship from the two groups of countries. Specifically, assuming that the institutional factors explain why some countries score consistently well on rates of entrepreneurship while others do not (Amorós and Bosma 2014), it is anticipated that those countries that were most hit by the global financial crisis may evidence several institutional weaknesses (or fragilities) that may affect the opportunities to create a new business. These fragilities are partly related to regulatory failures, compounded by over-reliance on market selfregulation, lack of transparency, lack of financial integrity, and irresponsible behavior (Năstase and Kajanus 2010). Considering this scenario, the spread of the systemic banking crisis not only affected economic growth and the labor market but also caused a number of constraints to new and growing firms having particular implications on high-quality entrepreneurship due to adverse conditions (Giotopoulos et al. 2017). Nevertheless, the global financial crisis may also be associated with fewer employment opportunities, which may be a good reason to push people into entrepreneurial activities due to lower paid jobs and it is also commonly associated with lower opportunity costs for new entrants (Simón-Moya et al. 2016). According to Arrighetti et al. (2016), the rate of entrepreneurial supply has decreased in those European countries that were most severely hit by the systemic banking crisis. The choice of national experts stems from the fact that they are very well informed about the entrepreneurial reality of their countries. Thus, the perception of a sample of National Entrepreneurship Experts (NES-GEM) derived from two group of countries is examined and the following research questions are addressed:

(1) Are institutional factor conditions important in shaping the entrepreneurial experts' perceptions of opportunites to create a new business?

(2) Do countries exposed to systemic banking crisis exhibit a pattern in the experts' perceptions of opportunities that differ significantly for business creation?

(3) Do institutional factor conditions have the same impact on entrepreneurial experts' opportunity perceptions regardless of the macroeconomic conditions experienced and trade openness?

To address the previous research questions, this study pairs a country-level dataset of the GEM project for entrepreneurial opportunities factors with information on countries affected by the recent global financial crisis and examines whether the experts' opportunities perceptions and their main drivers differ systematically across the two groups of countries. Moreover, it is tested if these changes vary with the degree of dependence on international trade exhibited by the country.

In order to divide the sample into those countries mostly affected by the global financial crisis versus the other countries, this study adopts the definition of a banking crisis used by Laeven and Valencia (2013). Accordingly, a crisis is identified as a systemic banking crisis when two conditions are met: first, there are significant signs of financial distress in the banking system; and second, significant banking policy intervention measures have been taken in response to losses in the banking system. In this vein, 44 countries were included 
in the analysis, comprising a total sample of 1771 respondents (National Entrepreneurship Experts). Of these, 766 are representative of the banking crisis countries and 1005 are representative of countries not affected by this crisis.

In terms of contributions, this study makes the following advances in the global entrepreneurship literature. First, this study addresses an area of the GEM model, the NES-GEM, that is under-researched. In fact, this project proposes "good constructs and measures" that can capture the various (formal and informal) aspects of institutions, which is in line with Gupta et al. (2012). Second, as previously mentioned, the study examines the impact of several institutional factor conditions and trade openness on the perception of an opportunity to create a business during a systematic banking crisis, thereby it fullfills an important gap in the literature. Third, the study includes the topic of the global financial crisis within the global entrepreneurship debate. Fourth, this study is in line with Bruton et al. (2010), who argued that institutional economics can be relevant for understanding which factors encourage opportunity entrepreneurial behavior with the goal of increasing economic growth. The paper is structured as follows: it starts with a presentation of the literature review and hypotheses; a description of the research setting and the main results then follow. Finally, some limitations and future research directions are identified.

\section{Literature review}

Several authors recognize that there are two major streams in institutional theory (Bruton et al. 2010). One stems from sociology and organizational theory and maintains that the major force driving institutions is the effort they make to achieve legitimacy and a stable framework in uncertain situations. The other relies on political science and economics and focuses on governance structures or ruling systems constructed by individuals. This orientation maintains that actors persistently build institutions that achieve the outcomes they desire, seldom asking about where preferences arise from or considering feed-back mechanisms (Bruton et al. 2010). Irrespective of the type of stream research, several authors maintain that different national institutional factors may contribute to different levels of entrepreneurial activity across countries (Urbano and Alvarez 2014) and, more specifically to increase the opportunities of creating a new business (or start-ups).

This study rests on the belief that the opportunity of creating a new business is likely to be influenced by the three key institutional dimensions proposed by Scott (1995). While the normative dimension incorporates social norms, values, and beliefs related to social behavior, the cultural-cognitive dimension relies on "taken-for-granted rules" and comprises collective understandings of the make-up of social reality as well as frames through which individuals and organizations interpret information (Bruton et al. 2010; Busenitz et al. 2000). In the opinion of Busenitz et al. (2000: p. 995), this dimension can be viewed as the "knowledge and skills possessed by the people in a country pertaining to establishing and operating a new business". Bosma et al. (2018) also included the education dimension within the cognitive dimension. Finally, the regulatory dimension considers the formal system of rules, laws, regulations, and government programs as important features to promote certain behaviors and inspect others' conformity to them (Busenitz et al. 2000). Bosma et al. (2018) included within the regulatory dimension 
variables such as regulatory burdens, labor market regulations, among others. In a recent study, Urbano et al. (2019) examined the institutional factors shaping entrepreneurial activity and their effect on economic growth.

\section{Opportunity to create a new business}

The opportunity recognition is the first central step in the entrepreneurship process. Yet, the debate over this notion of opportunity has been very intense due to the absence of a clear definition, which, in the words of Davidsson (2015), can be characterized as an "elusive concept". As this author noted, there is very little solid knowledge about what "the salient characteristics of "opportunities" are; how such entities can be idend and how to measure their characteristics in non-experimental settings, and what direct actormoderated effects they have on action and outcomes beyond initial attractiveness assessments" (Davidsson 2015, p. 675). This author puts forward a reconceptualization of the concept of opportunity applying it to the constructs of external enablers, new venture ideas, and opportunity confidence. Baron (2006) highlights aspects related to alertness, active search, prior knowledge of customers, and technology.

Shane and Venkataraman (2000) acknowledged that opportunities exist as an objective fact though they are not known to all individuals. Thus, an opportunity by definition is unidentified until discovered. There are individuals who are more sensitive to environmental shifts and have the capability to see gaps based on a valuable ability to search and scan the environment (Chandler and Friedman 2009; Kirzner 1973). Another perspective relies on the fact that entrepreneurs bring opportunities to existence through creative processes based on their efforts, actions, and active search (Sarasvathy et al. 2010). In this case, entrepreneurs are an integral part of opportunity occurrence as they invent what they believe to be reliable by resorting to a set of deep and diverse experiences as well as an extended network of resources and people (Wood and McKinley 2010). Specifically, there are two schools of thought in the way opportunities are found: discovery vs search (Chandra et al. 2009). The former assumes that opportunities are unknown until being discovered and that one cannot intentionally quest for something that one does not know exist, the latter relies on the fact that opportunities are identified through a purposeful, rational, and systematic process.

In turn, Welter and Smallbone (2011) acknowledged that entrepreneurship is influenced by external conditions, which affect the way entrepreneurs behave in regard to opportunity recognition, development, and business strategy. Within the debate of opportunity to create a new business, a different stream of research can be derived from the work of Alvarez et al. (2015), who claimed that the formation of an opportunity has been traditionally examined in isolation rather than understanding the context in which entrepreneurs may change or even may create institutions. These authors contend that opportunities are the result of purposeful and emergent actions that start an iterative cycle of change based on experimentation, learning from successful (or failed) actions, and non-predictive decision-making. It is generally accepted that determined entrepreneurs exploit opportunities and access resources they identify throughout their stakeholders in their environment to realize their growth expectations.

Yet, the dominant approach of institutional theory focuses mainly on the important role of institutions in molding individuals' actions (Acemoglu and Robinson 2008). As 
these authors acknowledged, institutions strongly influence individuals and organizations in different regions and countries, a point also stressed by Aparicio et al. (2016) who underlined the importance of culture, beliefs, and social values in the configuration of entrepreneurship in different countries. In the same line, Bruton et al. (2010) argued that the institutional framework is important to understand which factors stimulate entrepreneurial opportunities. Consistent with this, the NES-GEM project views opportunity to create a new business as a construct that includes a number of indicators that range from plenty of good opportunities for the creation of new firms, opportunities that people are able to take advantage of, opportunities that can be easily pursued by individuals, among others.

As previously mentioned, entrepreneurial activity and entrepreneurial opportunity perceptions can be crucial for economic growth, development, employment, and innovation (Aparicio et al. 2016; Simón-Moya et al. 2016; Urbano and Alvarez 2014). With the global financial crisis, important changes in the perceptions of opportunities for business creation can take place, particularly in a context in which public policies adopted by governments aim to stimulate the economic recovery process.

This study posits that the financial crisis affects directly and negatively these opportunity perceptions namely because of the increased uncertainty about the future. Also, the financial crisis can affect the perception of good oportunities in an indirect way. For example, when governmental agencies change their behavior in times of crisis, or when market regulations are adapted to deal with some aspect of the crisis, or even if the social image of the entrepreneur (to name a few reasons) is changed in a way that interferes with the positive effects impacting on entrepreneurial activities. These indirect effects may reinforce (or attenuate) the negative economic consequences of the crisis and can shed some light on possible stimuli used by public authorities in their counter-cyclical interventions.

Additionally, this study also examines whether countries more exposed to international conditions (or economic freedom) would have a lower negative impact of the adverse economic environments on opportunities to create a new business. Using GEM data from 11 EU countries, Mandić et al. (2017) found a positive and significant effect of institutions operating in a context of economic freedom and activity, and subsequently entrepreneurial opportunities. Also, Hall et al. (2013) found a positive association between institutions that promote economic freedom (and international conditions) and entrepreneurial activity (or opportunities). Considering the above, the following hypothesis is presented:

H1a: Countries exposed to a systemic banking crisis would evidence a lower level of opportunities to create a new business.

H1: This effect is moderated by country's international trade exposure)

Relying upon NES-GEM, this study uses cultural and social norms, internal market openness, government programs, education and training, and social image of the entrepreneur as proxy variables of Scott's (2014) three institutional dimensions (normative, regulative, and cognitive). Next, a detailed analysis will be developed for each proxy variable and this will be linked to the opportunity to create a new business. 


\section{The normative dimension: Cultural and social norms and internal market openness}

The normative dimension enforces restrictions on social behavior through values and social norms (Scott 2014). While values are "conceptions of the preferred or the desirable together with the construction of standards to which existing structures or behaviors can be compared or assessed", social norms specify "how things should be done; they define the legitimate means to pursue valued ends" (Scott, 2014, p. 64). The normative dimension is concerned with "what people consider to be legitimate, acceptable ways of gaining something that has broad societal approval" (Valdez and Richardson, 2013, p. 1157). These authors consider an entrepreneur's perceptions of cultural and societal norms regarding entrepreneurial activity as a good indicator of the normative dimension. Similarly, Urbano and Alvarez (2014) associated the normative dimension with the culture dimension; therefore, this study uses cultural and social norms and internal market openness as proxy variables of the normative dimension.

Cultural and social norms are important because they shape human behavior and can be viewed as a collective phenomenon as they are shared by people who live within the same social environment (Hofstede 1991). Culture assumes a collective nature and the values associated with it may vary within and among nations, though there is a considerable overlap between countries' cultures. As acknowledged by Arabiyat et al. (2019), the GEM model distinguishes between national culture viewed as "cultural context" and "entrepreneurial cultural and social norms". While the former are treated as a contextual aspect, the latter involve context-specific beliefs and attitudes toward entreprenurship. The study of culture and the ways in which it interacts with other contextual factors like institutions and economic development has great relevance to understand entrepreneurial behavior around the world (Hayton and Cacciotti 2014). These authors also suggested that there are a number of other variables, such as rates of inward investment, national innovation, or entrepreneurship policies that are expected to interact with cultural factors. In the view of Meek et al. (2010, p. 494), "social norms could shed light on how group-level values impact the individual-level decision making" and, as a result, on the level of opportunity to create a new business.

Additionally, the normative system boosts market openness and freedom, which are of particular importance for the opportunity to create a new business (Sambharya and Musteen 2014). For McMullen et al. (2008), economic freedom can be translated into property rights and labor and is associated with opportunity-entrepreneurship as it enables one to exploit new market segments, enjoy wider profit margins, and is less sensitive to changes in tax rates and inflationary pressures than their necessitymotivated counterparts (McMullen et al. 2008, p. 890).

In countries with economies that have lower internal market openness or lower market freedom, such as the case, for instance, of a country operating under the auspices of the International Monetary Fund (IMF), reflected in rigid rules, increased taxation, among others, it is likely that entrepreneurship will be mainly driven by the informal sector (Sambharya and Musteen 2014). The excessive control of economic activities by a prisoned government may partly distort "competitive forces and make entry by entrepreneurs that seek to pursue opportunities that can potentially disrupt the status quo difficult" (Sambharya and Musteen 2014, p. 319). Considering the previous discussion, the following hypothesis is proposed: 
H2: The normative dimension will strongly (and significantly) impact on the opportunity to create a new business.

(H2a: This effect is moderated by adverse economic conditions (as well as by country's international trade exposure)

\section{The cultural-cognitive dimension: Higher education and training and social image}

The second institutional pillar proposed by Scott (2014) is the cultural-cognitive dimension, which comprises "the shared conceptions that constitute the nature of social reality and create the frames through which meaning is made" (Scott, 2014, p. 67). This dimension is important as it relates to "how societies accept entrepreneurs, inculcate values, and even create a cultural milieu whereby entrepreneurship is accepted and encouraged" (Bruton et al. 2010, p. 423). It also reflects the cognitive structures and social knowledge shared by people in a given country (Urbano and Alvarez 2014), an issue also emphasized by Busenitz et al. (2000) who underlined the importance of knowledge and skills (or education) connected to establishing and operating a new business possessed by the people in a country.

Concerning higher education and training, it impacts on national-level entrepreneurial activity through two mechanisms: (1) the ability to recognize and pursue entrepreneurial economic opportunities; (2) instilling individuals with the necessary capabilities and technical skills required to launch new start-ups (Levie and Autio 2008). Education also enhances an individual's cognitive ability making the recognition of a potential opportunity easier (Levie and Autio 2008). In line with Shane and Venkataraman (2000), knowledge building helps to identify specific entrepreneurial opportunities in response to technological changes (Giotopoulos et al. 2017). Furthermore, when individuals evidence higher skills, knowledge, high social capital, and experience to start a business, they are more likely to engage in an opportunity-driven entrepreneurship. According to Bowen and De Clercq (2008), a country's level of educational capital targeted at entrepreneurship will positively affect the allocation of entrepreneurial efforts toward high-growth activities. Conversely, a low level of technical and business skills inhibits entrepreneurs from starting a new venture (Gnyawali and Fogel 1994). Highly educated individuals are more aware of opportunities, are more motivated to pursue their exploitation (Eckhardt and Shane 2003), and have more confidence about the feasibility of their project, fostering their self-efficacy (Arrighetti et al., 2016).

In the context of the global financial crisis, it is likely that "the intrinsic motivation in well-educated individuals linked to their attempts to fulfill their aims in life may outweigh the extrinsic material-reward and wealth-seeking motives, since credit squeeze and austerity measures across Europe could discourage wealth attainment" (Giotopoulos et al. 2017, p. 917). In other words, in adverse economic conditions, individuals with high levels of human capital are likely to better perceive opportunities to create a new business, particularly with regard to high-potential businesses (Giotopoulos et al. 2017).

Concerning the social image of the entrepreneur, individuals are often attracted to self-employment if they perceive that being associated with the reference group of entrepreneurs provides them with higher status, prestige, and a successful image (Parker and van Praag 2010). Several authors argue that beyond the distinctive traits 
of people who become entrepreneurs, there is another possible explanation which is related to social mobility processes associated to entrepreneurship even if it is reflected in a wage disadvantage (Sørensen and Sharkey 2014). Additionally, as stated by Aleksandrova and Verkhovskaya (2016), the perception of entrepreneurship as a successful career choice and an entrepreneur's high status (or a favorable social image) given by society has a positive impact on entrepreneurial activities, and subsequently, in our view, on entrepreneurial opportunity to create a business.

A favorable social image of the entrepreneur is positively and frequently associated in the press (or social media) with the dissemination of successful stories and a general social perception that entrepreneurs are competent and resourceful individuals (Pinho and Thompson 2017). For instance, higher media attention for new business achievements has a positive impact on entrepreneurship (Urbano and Alvarez 2014). Yet, it should be noted that for the vast majority of the self-employed, success may be elusive and the entrepreneurial activity may be short-lived, particularly in a context of an unpredictable global crisis event. Hence, the following hypothesis is proposed:

H3: The cultural-cognitive dimension will strongly (and significantly) impact on the opportunity to create a new business.

H1: This effect is moderated by adverse economic conditions (as well as by country's international trade exposure)

\section{The regulatory dimension: Government programs and regulatory protection}

The third institutional pillar proposed by Scott (2014) is the regulatory dimension, which comprises the capacity to establish laws, regulations, and government programs in order to foster certain behaviors and inspect others' conformity to them (Bruton et al. 2010; Busenitz et al. 2000). For the purpose of this study, government programs regarding entrepreneurship and regulatory protection are used as proxy variables of the regulatory pillar.

According to several authors, government regulation of economic activity promotes entrepreneurial activity in such a way that the focus is more centered on markets or governments (collective actions) rather than on individual actions (Alvarez et al. 2015; McMullen et al. 2008; Valdez and Richardson 2013; Urbano et al. 2019). According to Raza et al. (2019), government regulations establish and apply policies and laws that control a country's business activities.

It is generally accepted that government programs and their intrinsic quality may influence entrepreneurial activities. In fact, the level of regulatory complexity may represent a significant obstacle to entrepreneurship in such a way that entrepreneurs pursuing an attractive business opportunity may be inhibited to reach their objectives due to cumbersome and time consuming regulations (Sambharya and Musteen 2014). In other words, there are a number of government programs, rules and policies that are perceived negatively by potential entrepreneurs, particularly those associated with the extended length of time required to start a business, high costs to obtain permits or licenses, high entry barriers, difficulty in closing a business, rigidity in labor regulations, and requirements of minimum capital to start a business. Their implications not only affect innovation but also induce a lower propensity to maximize the potential 
opportunity to create a new business (Gnyawali and Fogel 1994; Urbano and Alvarez 2014).

Concerning regulatory protection, it may also represent a significant barrier to entrepreneurship. Dealing with complex administrative processes and particularly in the event of running the risk of losing private property, potential entrepreneurs may be discouraged from engaging in entrepreneurial activities (McMullen et al. 2008).

Regulatory protection relates to the degree to which government creates the right to property and enforces the written laws to protect those rights. One key driving force of a free market economy is the ability to accumulate wealth; therefore, it is crucial to ensure protection of private assets (McMullen et al. 2008). If the state does not ensure an efficient rule of law towards protection of private and intellectual property, individuals are less likely to invest in improving their assets and produce wealth (DeSoto 2000). Lack of protection of property rights also diminishes entrepreneurs' trust with regard to starting a new business, avoiding making long-term plans (McMullen et al. 2008). In other words, an unfriendly environment with regard to property rights may in the long run constrain the level of capital investment and place capital under fiscal and regulatory barriers, so that it affects the opportunity to create a new business. Hence, the following hypothesis is proposed:

H4: The regulatory dimension will strongly (and significantly) impact on the opportunity to create a new business.

(H4a: This effect is moderated by adverse economic conditions (as well as by country's international trade exposure)

The model presented in Fig. 1 depicts the relationships between the institutional factors and their impact on the opportunity to start-up.

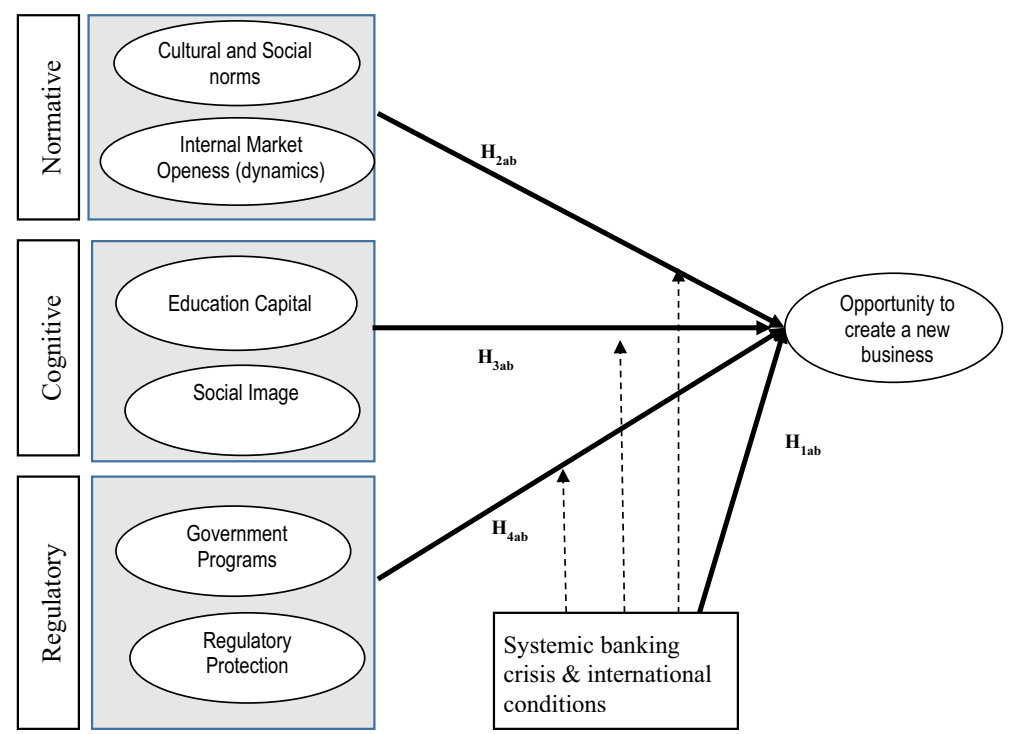

Fig. 1 Proposed hypotheses 


\section{Research methodology}

To test the proposed model, a full sample of 1771 national experts was considered, but after dropping missing values, there remained 998 responses to use in regressions, of which 373 are representative of the countries affected by the banking crisis and 625 experts are from the unaffected countries (see Table 1 for details).

This study adopts the classification criteria proposed by Laeven and Valencia (2013) and follows Adams-Kane et al. (2013), in which a crisis is identified as a systemic banking crisis. For the purposes of this study, the notion "systemic banking crisis" will be used interchangeably with the notion of global financial crisis. Table 1 identifies the countries belonging to each of the groups that are surveyed in the GEM NES 2012 edition, which corresponds to the first year after the global financial crisis period considered in the work of Laeven and Valencia (2013). The crisis variable is a binary variable that takes on the value one if a systemic banking crisis occurs and zero otherwise. Regarding the measurement of a country's exposure to international markets, this study uses a dicothomous variable that takes on the value one if the country's trade (\% of GDP) exceeds 100\% (according to 2011 World Bank data) and zero otherwise. More specifically, international trade is the sum of exports and imports of goods and services measured as a share of gross domestic product.

\section{Measurements}

To test the proposed hypotheses, the GEM data are used, particularly from the National Expert Survey (NES). The NES-GEM collects the views of national experts on entrepreneurship on a wide range of aspects of a country's socio-economic milieu that are believed to have a significant impact on national entrepreneurship. Each institutional dimension is associated with a number of Entrepreneurial Factor Conditions (EFCs) that are included in the NES-GEM survey (Fig. 1). The indicators for each institutional sub-dimension are provided in Appendix Table 4.

\section{Dependent variable (opportunity to create a new business)}

Concerning the opportunity to create a new business, it addresses the existence of good opportunities for the creation of new firms and considers whether people in general are able to take advantage of these opportunities. It also identifies whether opportunities have increased significantly in the past 5 years, among others.

Measures of opportunity are based both on the five single items inquired in GEM NES 2012 about perceived opportunity (questions K01-05 in Appendix Table 4) and also on a single variable "Perception of the existence of opportunities" based on the Component Principal Analysis (CPA) that summarizes all items. (i.e., NES12_KSUM). In other words, according to the GEM manual, "Perception of the existence of opportunities" is a CPA summary of the first five questions (Appendix Table 4). The GEM Data Team calculates a principal component analysis on the global NES data obtained each year. The blocks are summarized in one or two principal components and these new quantitative and continuous variables are those that represent the status of the entrepreneurial framework conditions. The scores of these variables are included in the comparative file for each economy after assessing their reliability properties, such as Cronbach's alpha. 


\section{Results and discussion}

This study investigates the impact of three institutional pillars (normative, cognitive, and regulative) on the opportunity to create a new business (Appendix Table 4). Table 2 illustrates the direct estimates of different institutional factor conditions on the opportunity to create a business, which enables one to confirm the proposed hypotheses. Several different measures for the dependent variable, extracted from the NES survey, and presented in Appendix Table 4 are used and the estimation results are shown in Table 2.

Relying on Table 2, which includes all cases, first, it can be concluded that the institutional factor conditions considered in the present study have globally a significant impact on the opportunity to create a business. Additionally, results seem to indicate that countries exposed to (a) systemic banking crisis and (b) more exposed to international conditions (because their economies depend more on international trade than the others) would evidence a lower level of opportunities to create a new business. These results seem to suggest that $\mathrm{H} 1 \mathrm{a}$ and $\mathrm{H} 1 \mathrm{a}$ are partially supported by the data.

With regard to the normative pillar, which emphasizes cultural and social norms and arbitrary aspects of social life, it includes two sub-components: cultural and social norms and internal market openness. Results indicate that the cultural and social norm sub-component has a significant and a positive impact on the opportunities to create a new business $(\beta=0.108 ; p<0.01)$. Concerning the internal market openness subdimension, it was divided into two sub-categories: the internal market openness (or dynamics) and the internal market burdens. While the first sub-category is not supported by the data $(\beta=0.029 ; p>0.05)$, the second one is $\beta=0.232 ; p<0.01$. Overall, this indicates that $\mathrm{H} 2$, which maintains that the normative dimension will impact on the opportunity to create a new business, is supported by the data.

Concerning the cultural-cognitive pillar, which underlines the shared understanding that forms social reality and defines what is meaningful to members of society (Scott 2014), it comprises two sub-components: education and social image. With respect to education, it was sub-divided in two subcategories. The primary/secondary education, which is not supported by the data $(\beta=-0.044 ; p>0.05)$, and the level of education at vocational, professional, college, and universities, which evidences a negative direction. Although this last result is counter intuitive, a possible explanation for this result may be possibly related to the fact that higher education in entrepreneurship is usually associated with a specific type of entrepreneurship, the opportunity entrepreneurship, which is based on innovation and development of new products. This type of opportunity entrepreneurship is usually associated with innovation-driven countries. As most of the countries that fit in this category are under the global financial crisis pressure, a new type of entrepreneurship may arise, which is more oriented to necessity entrepreneurship. In such circumstances, higher education in entrepreneurship may assume a different role than it would assume in a non-crisis context. Irrespective of that, more research needs to be conducted, particularly by considering these two categories as potential mediators or moderators.

With regard to the sub-category of social image, it is supported by the data $(\beta=$ $0.226 ; p<0.01$ ). This seeems to suggest that a favorable social image of the entrepreneur regarding entrepreneurship will strongly impact on the opportunity to create a new business. This result shows the value of entrepreneurs in society, which has a positive and significant effect on experts' opportunity perceptions. The social image of the entrepreneur seems to be a critical factor to explain the opportunity to create a new firm 


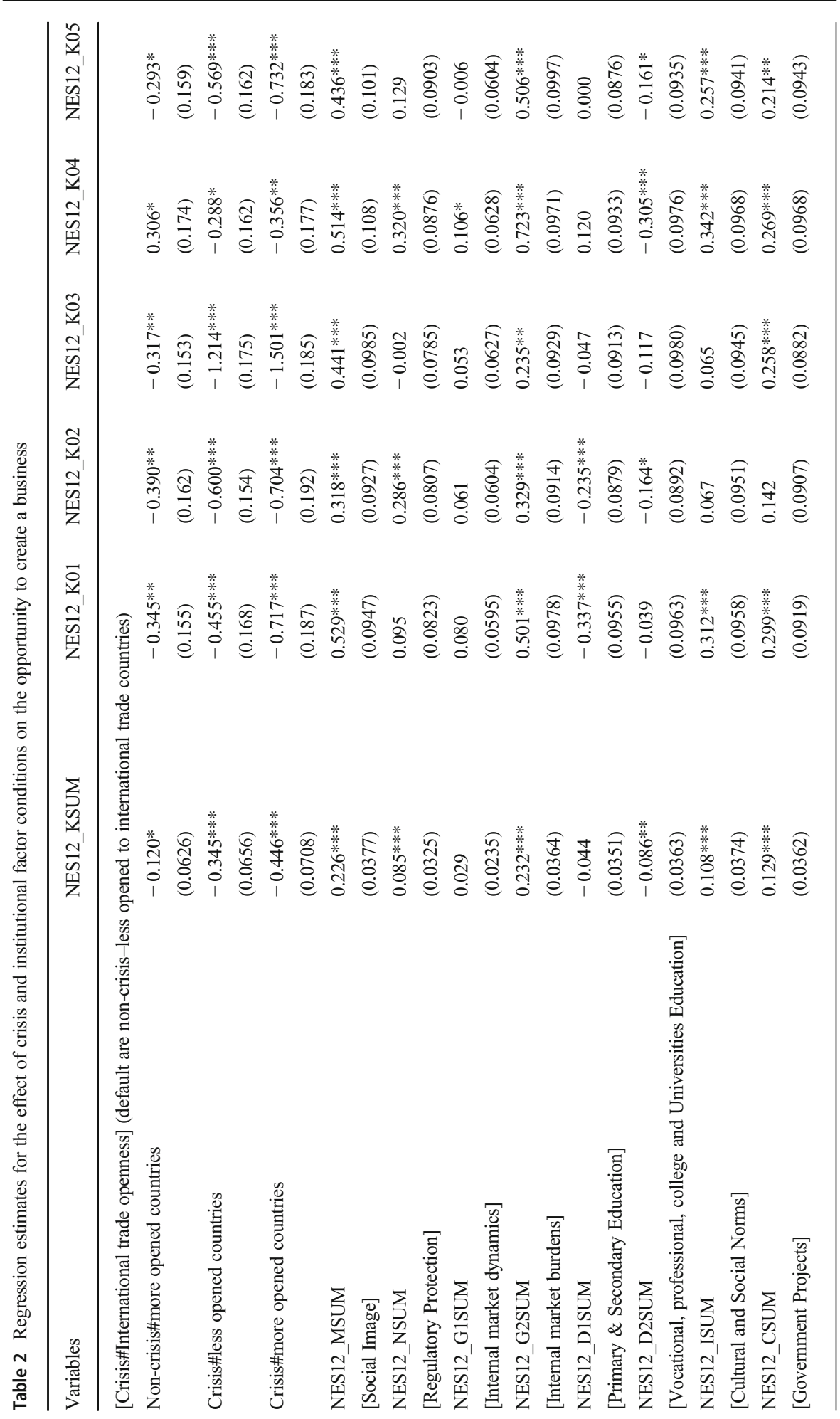




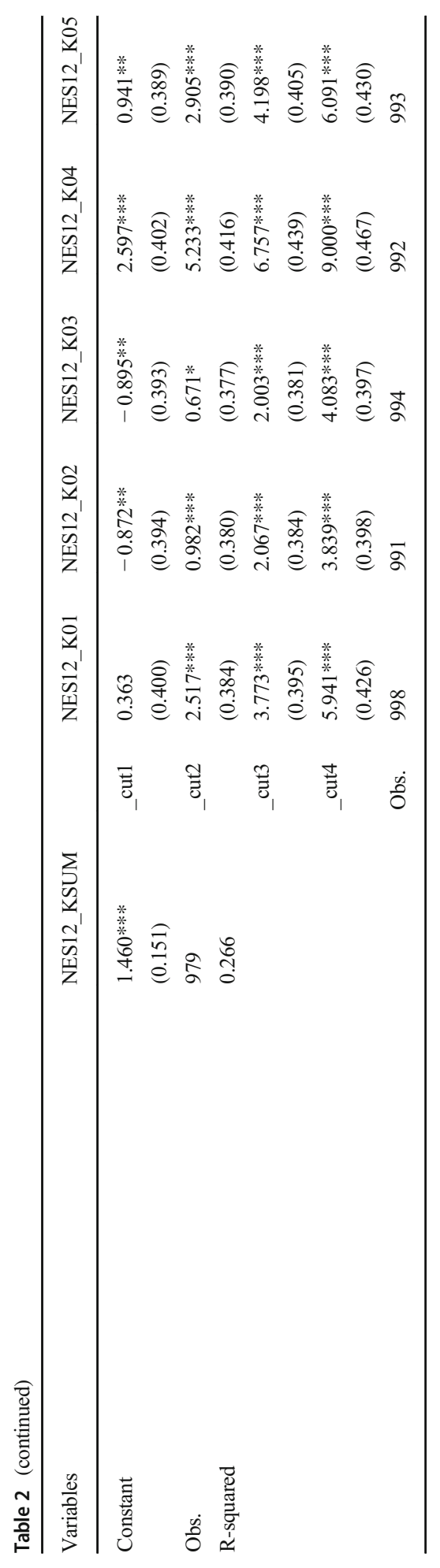


within the studied countries. Overall, results indicate that $\mathrm{H} 3$, which maintains that the cultural-cognitive dimension will impact on opportunity to create a new business, is supported partially due to education by the data.

Finally, the regulatory pillar, which emphasizes formalized structural aspects within society, includes two sub-categories: the government programs and the regulatory protection. With regard to the former, it is assumed that as government programs are favorable towards entrepreneurship, there is a positive impact on the opportunity to create a new business. Results depicted in Table 2 support this relationship $(\beta=0.129 ; p<0.01)$. The second sub-category relates to regulatory protection (e.g., intellectual property rights, patents, copyrights, among others), which maintains that favorable regulatory protection regarding entrepreneurship will strongly impact on the opportunity to create a new business $(\beta=0.085 ; p<0.01)$. Overall, it can be concluded that the regulatory dimension will strongly impact on the opportunity to create a new business, supporting $\mathrm{H} 4$.

To conclude, considering the overall sample, the three institutional factor conditions considered in this study evidenced a positive and strong impact on the opportunity to create a new business. In other words, results confirm the relevant impact of the normative, cultural-cognitive, and regulatory on the opportunity to create a business. This is in line with several authors who stated that these three dimensions gauge a country's ability to support high-impact entrepreneurship (Stenholm et al. 2013).

This study went a step further and examined the "Hia" (where i represents each of the opportunities' determiners tested) in which we consider two interacting variables, namely: (a) the systemic banking crisis and (b) the exposure to international conditions (assessed here by each country's exposure to international markets). In our regressions, when testing the interaction of the independent variables with trade openness, we found that the models in Table 2 were always a better econometric approach. Therefore, we concluded that we had no evidence to support the hypothesis that instituitons could be more effective in less open economies. By contrast, several of the crisis variables' interactions seem to have a significant role in atenuating/enhancing opportunity perceptions in more adverse economic environments such as the systemic banking crisis. Table 3 illustrates the result of this analysis.

As depicted in Table 3, results suggest that the systemic banking crisis may reinforce the role of those national cultures that value individual success, encourage risk-taking, creativity and innovativeness on creating good conditions for the opportunity to create a business. In other words, cultural and social norms that belong to the normative pillar are a powerful push factor that stimulates people's opportunities to create a business and that also seems to be particularly effective in difficult economic times. This is in line with several authors who maintained that values, beliefs, and norms may differently influence the entrepreneurial activity of a country's residents (Busenitz et al. 2000; Descotes et al. 2011).

Another interesting result indicates that the systemic banking crisis reduces the positive effect associated with the social image of the entrepreneur. This social image (or status) is commonly attached to individuals on the basis of their apparent possession of certain attributes as perceived by other members of their social group. The importance of this perceived social image on good opportunities for starting a business was negatively affected by adverse economic conditions.

Despite the role of trade openness in augmenting the crisis impact on opportunities to create a business, it was not observed or at least it was not so evident when considering indirect effects such as those postulated in the remaining "Hia" hypothesis. A possible 


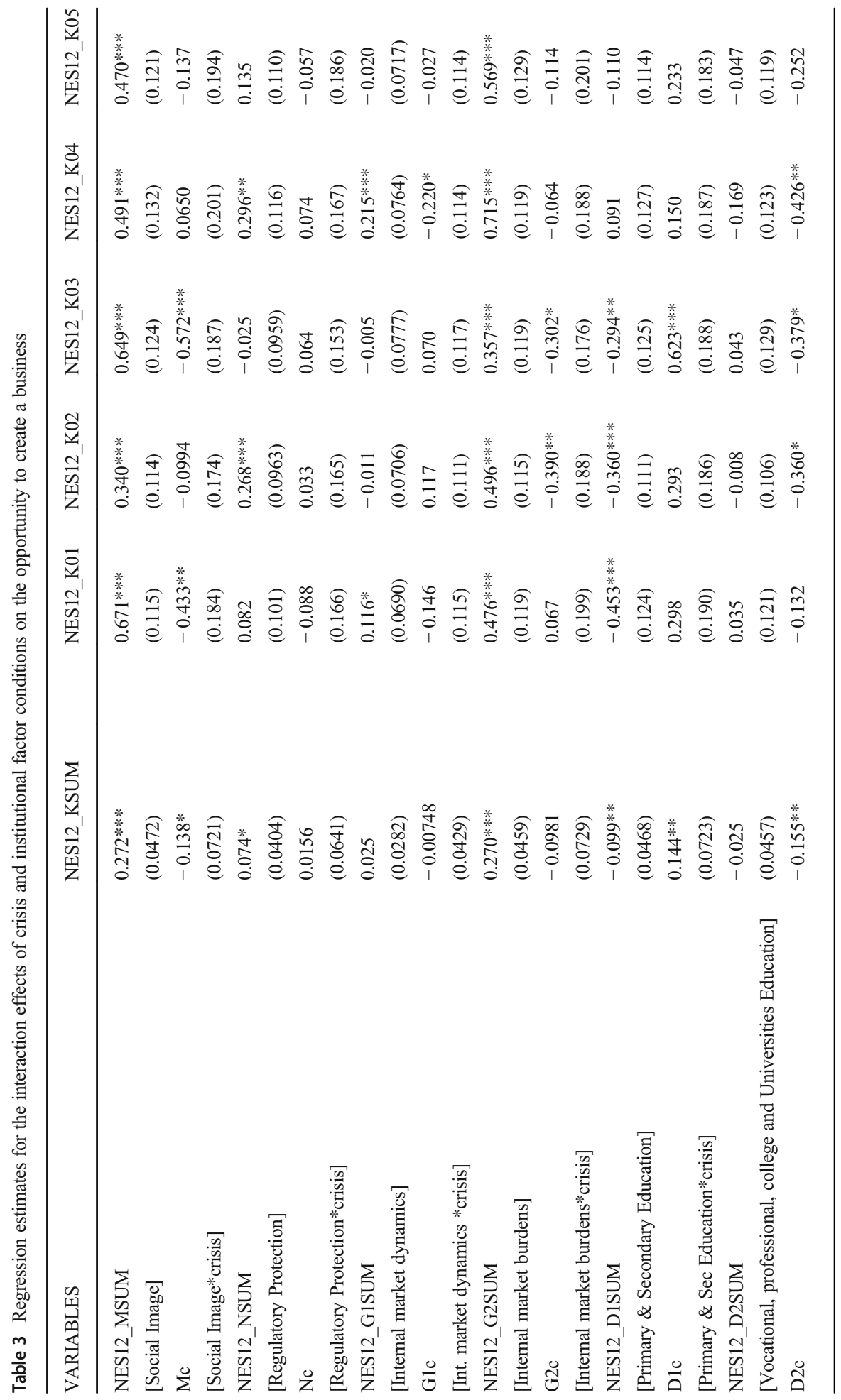




$$
\text { E }
$$


explanation for this may lie in the fact that irrespective of international trade conditions, institutional factors (regulative, normative, and cultural-cognitive) are important to explain the opportunity to create a business. These results are in line with the findings of Urbano and Alvarez (2014), who found that a favorable regulative, normative, and cultural-cognitive dimensions increase the probability of being an entrepreneur. The only difference from their study is that we have applied the constructs to national experts' opinions.

To sum up, it can be concluded that the previous results (Table 3) suggest that the systemic banking crisis as well as the international trade conditions kept the effect of institutional factor conditions on the opportunity to create a business relatively unchanged.

\section{Contributions and implications of the study}

This study follows Baumol's (1990) reasoning that over centuries, certain societies favored certain institutional structures of reward in the development of entrepreneurship, whereas others did not promote these institutional mechanisms and structures of reward. This occurred to such an extent that these societies dissuaded national (and local) elites from developing entrepreneurial productive activities which, in the long run, inhibited the dissemination of technical progress (Baumol 1990).

The results of this study have relevance for theory and practice. The primary theoretical contribution lies in investigating how several institutional factor conditions, viewed by national entrepreneurial experts, impact on the opportunity to create a business. Second, this study concluded that countries exposed to homecountry crisis which are more dependent on international trade than the others exhibit a pattern in the perceptions of good opportunities for business creation that differ significantly from the other countries.

Third, considering the global sample of countries and examining the normative dimension, which includes both cultural and social norms and market openness, this study finds that it has a significant and positive impact on the opportunities to create a new business. Cultural and social norms seem to be particularly relevant in times of crisis, increasing significantly the perception of opportunities and thus helping governments to succeed in their recovery policies. With regard to the cultural-cognitive dimension, the study concludes that the first sub-category of basic education (primary/secondary) is not supported by the data while the second one is. However, this second sub-category evidences a negative direction which may be seen as a counter-intuitive result and thus deserving further attention in future research. The study also concludes that a favorable social image of the entrepreneur will strongly impact on the opportunity to create a new business. This shows the importance and value of entrepreneurs in society, which has a positive and significant effect on experts' opportunity perceptions. In relation to the regulatory dimension, it is assumed that as government programs are favorable towards entrepreneurship, there is a positive impact on the opportunity to create a new business. Also, a favorable regulatory protection regarding entrepreneurship will strongly impact on the opportunity to create a new business.

Fourth, concerning the moderating effects of systemic banking crisis and the international conditions on the relationship between institutional factors conditions and the opportunity to create a business, the following results were found. First, the effect of all studied institutional factor conditions on the opportunity to create a business does not differ significantly for the two sub-samples (systemic non-banking crisis versus banking crisis countries) with the exception related to the cultural and social norms and social image dimensions. Cultural and 
social norms seem to be more important for opportunity perceptions in the sub-sample of countries affected by the global crisis and social status seems to be more important for opportunity perceptions in the sub-sample of non-crisis countries (Table 3). Second, no solid evidence was found in the present study that international conditions strongly moderate the relationship between institutional factor conditions and the opportunity to create a business. Thus, we did not find evidence to support the hypothesis that instituitons could be more effective in more open economies.

Fifth, by using the NES-GEM data, this study explores an area of GEM that is considered as under-researched (Amorós and Bosma 2014). It should be noted that most studies relying on the GEM project have been mainly based on the "Adult Population Survey" data with very few studies addressing the National Expert Survey (NES) either from a single national or from an international based perspective. This argument was developed by Amorós et al. (2013), who contend that there are a number of entrepreneurial framework conditions (EFCs) identified by the GEM model that have not been the subject of much analysis. In the same line, Bruton et al. (2010) found that studies using both multi-country databases and institutional theory are very scarce. It is also relevant to notice that this database is formed by national experts with a substantial range of backgrounds and knowledge about each country (Reynolds et al. 2005).

From a practical perspective, this study is useful for designing a supportive institutional background that fosters the creation of a set of opportunities to create a business within an adverse context. Finally, the findings and implications of this study should be considered in light of several limitations. One possible limitation is the use of a perception based measure for the creation of opportunities, with the perceptions of national specialists in entrepreneurship being our main dependent variable. However, this limitation is transversal to all studies exploring the NES-GEM database. Another limitation relates to the choice of the proxy variables of Scott's institutional dimensions. This study relies mainly on the NES-GEM variables; however, other studies considered other variables to measure the normative, cultural-cognitive, and regulative dimensions (Urbano and Alvarez 2014; Busenitz et al. 2000; among others). For instance, Arabiyat et al. (2019) in a recent a recent study included a vast number of variables from different data bases (NES-GEM, APS-GEM, GCI, WEF). Still, another limitation is related with the use of cross-sectional data, i.e., each sub-sample only covers 1 year (year 2012), which does not capture the dynamic processes of the global economic crisis.

Future studies could extend this work by investigating the nature of global crises, particularly the one we are living now, the COVID 19, and the role of certain institutions, particularly those related with the health sector to minimize the effects of this global crisis. As Doern et al. (2019) observed in a recent study, the implications of crises for entrepreneurship have been found to be negative and positive. As they noted, the negative effects are widely known, namely business failure, contraction, and resource losses. However, crises can also provide the impetus for developing new opportunities and resource gains. Thus, examining the nature of a global crisis (economic recession, natural disaster, global health pandemic, etc.) may bring important insights for future government policies and actions. At the same time, another question that deserves further attention is what the entrepreneur who is well integrated and knows their community quite well can do in order to minimize certain institutional fragilities and address specific needs of individuals by supplying critical resources in the aftermath of a crisis (Grube and Storr 2018). 


\title{
Appendix
}

Table 4 The impact of three institutional pillars

\author{
Opportunity to create a new Business-K01-K05 (five Items) \\ In my country ... \\ Dependent Variable 1. there are plenty of good opportunities for the creation of new firms \\ 2. there are more good opportunities for the creation of new firms than there are \\ people able to take advantage of them \\ 3. good opportunities for new firms have considerably increased in the past five years \\ 4. individuals can easily pursue entrepreneurial opportunities \\ 5. there are plenty of good opportunities to create truly high growth firms
}

Cultural, social norms and society support-I1-I5 (five items)

In my country the national culture ...
NORMATIVE
1. is highly supportive of individual success achieved through own personal efforts
DIMENSION
2. emphasizes emphasizes self-sufficiency, autonomy, and personal initiative
3. encourages entrepreneurial risk-taking
4. encourages creativity and innovativeness
5. emphasizes the responsibility that the individual has in managing his or her own life

Internal market dynamics (G1) (two items)

In my country ...

1.the markets for consumer goods and services change dramatically from year to year

2.the markets for business-to-business goods and services change dramatically from year to year

Internal market burdens (G2) (four items)

1.new and growing firms can easily enter new markets

2.the new and growing firms can afford the cost of market entry

3.new and growing firms can enter markets without being unfairly blocked by established firms

4.the anti-trust legislation is effective and well enforced

Entrepreneurial level of education at Primary and Secondary (D1)

In my country teaching in primary and secondary education ...

1.encourages creativity, self-sufficiency, and personal initiative

2.provides adequate instruction in market economic principles

3.provides adequate attention to entrepreneurship and new firm creation

Entrepreneurial level of education at vocational, professional, college and universities (D2) In my country ...

Cognitive dimension $\quad$ 1.Colleges and universities provide good and adequate preparation for starting up and growing new firms

2.the levelof business and management education provide good and adequate preparation for starting up and growing new firms

3.the vocational, professional, and continuing education systems provide good and adequate preparation for starting up and growing new firms

Social image-M1-M5 (five items)

In my country ...

1.the creation of new ventures new ventures is considered an appropriate way to become rich 
Table 4 (continued)

2.most people consider becoming an entrepreneur as a desirable career choice

3.successful entrepreneurs have a high level of status and respect

4.you will often see stories in the public media about successful entrepreneurs

5.most people think of entrepreneurs as competent, resourceful individuals

\section{Government programs-C1-C6 (six items)}

In my country ...

Regulatory dimension 1 . a wide range of government assistance for new and growing firms can be obtained through contact with a single agency

2. science parks and business incubators provide effective support for new and growing firms

3. there are an adequate number of government programs for new and growing businesses

4. the people working for government agencies are competent and effective in supporting new and growing firms

5. almost anyone who needs help from a government program for a new or growing business can find what they need

6. Government programs aimed at supporting new and growing firms are effective

\section{Regulatory protection (N1-N5) (five items)}

In my country ...

1. the Intellectual Property Rights (IPR) legislation is comprehensive

2.the Intellectual Property Rights (IPR) legislation is efficiently enforced

3.the illegal sales of 'pirated' software, videos, CDs, and other copyrighted or trademarked products is not extensive

4.new and growing firms can trust that their patents, copyrights, and trademarks will be respected

5.it is widely recognized that inventors' rights for their inventions should be respected

\section{References}

Abdesselam R, Bonnet J, Renou-Maissant P, Aubry M (2017) Entrepreneurship, economic development, and institutional environment: evidence from OECD countries. J Int Entrep 16(4):504-546

Acemoglu D, Robinson J (2008) Persistence of power, elites, and institutions. Am Econ Rev 98(1):267-293

Adams-Kane J, Caballero JA, and Lim JJ (2013) "Foreign bank behavior during financial crises", World Bank Policy Research Paper No. 6590, World Bank, Washington

Aleksandrova E, Verkhovskaya OR (2016) Motivations to start businesses: institutional context. Working Paper No. 2 (E), Graduate School of Management. St. Petersburg State University, Saint Petersburg

Ali R, Muffatto M (2019) The influence of formal institutions on the relationship between entrepreneurial readiness and entrepreneurial behaviour. J Small Bus Enterp Dev 26(1):133-157

Alvarez S, Young S, Woolley J (2015) Opportunities and institutions: a co-creation story of the king crab industry. J Bus Ventur 30:95-112

Amorós J, Bosma N (2014) Global entrepreneurship monitor 2013 global report: Fifteen years of assessing entrepreneurship across the globe. Available at: http://www.gemconsortium.org/docs/3106/gem-2013global-report/. Accessed 10 Nov 2016

Amorós J, Bosma N, Levie J (2013) Ten years of global entrepreneurship monitor: accomplishments and prospects. Int J Entrep Ventur 5(2):120-152 
Aparicio S, Urbano D, Audretsch D (2016) Institutional factors, opportunity entrepreneurship and economic growth: panel data evidence. Technol Forecast Soc Exch 102:45-61

Arabiyat T, Mdanat M, Haffar M, Ghoneim A, Arabiyat T (2019) The influence of institutional and conducive aspects on entrepreneurial innovation. J Enterp Inf Manag 32(3):366-389

Arrighetti A, Caricati L, Landini F, Monacelli N (2016) Entrepreneurial intention in the time of crisis: a field study. Int J Entrep Behav Res 22(6):835-859

Baron R (2006) Opportunity recognition as pattern recognition: how entrpreneurs "connect the dots" to identify new business opportunities. Acad Manag Perspect 20(1):104-119

Baumol W (1990) Entrepreneurship: productive, unproductive, and destructive. J Polit Econ 98(5):893-921

Bosma N, Content J, Sanders M, Stam E (2018) Institutions entrepreneurship, and economic growth in Europe. Small Bus Econ 51:483-499

Bowen H, De Clercq D (2008) Institutional context and the allocation of entrepreneurial effort. J Int Bus Stud 39:747-767

Bruton G, Ahlstrom D, Li H (2010) Institutional theory and entrepreneurship: where are we now and where do we need to move in the future? Entrep Theory Pract 18:43-62

Busenitz L, Gómez C, Spencer J (2000) Country institutional profiles: unlocking entrepreneurial phenomena. Acad Manag J 43(5):994-1003

Chandler G, Friedman H (2009) Does self-efficacy affect entrepreneurial investment? Strateg Entrep J 3(3): $241-260$

Chandra Y, Styles C, Wilkinson I (2009) The recognition of first time entrepreneurial opportunities. Int Mark Rev 26(1):30-61

Davidsson P (2015) Entrepreneurial opportunities and the entrepreneurship nexus: a re-conceptualization. J Bus Ventur 30:674-695

Descotes R, Wallister B, Holzmüller H, Guo X (2011) Capturing institutional home country conditions for exporting SMEs. J Bus Res 64(2):1303-1310

DeSoto H (2000) The mystery of capital: why capitalism triumphs in the west and fails everywhere else. Basic Books, New York

Doern R, Williams N, Vorley T (2019) Special issue on entrepreneurship and crises: business as usual? An introduction and review of the literature. Entrep Reg Dev 31(5-6):400-412. https://doi.org/10.1080 /08985626.2018.1541590

Eckhardt J, Shane S (2003) Opportunities and entrepreneurship. J Manag 29:333-349

Giotopoulos I, Kontolaimou A, Tsakanikas A (2017) Drivers of high-quality entrepreneurship: what changes did the crisis bring about? Small Bus Econ 48:913-930

Gnyawali DR, Fogel DS (1994) Environments for entrepreneurship development: key dimensions and research implications. Entrep: Theory Pract 18(4):43-62

Grube LE, Storr VH (2018) Embedded entrepreneurs and post-disaster community recovery. Entrep Reg Dev 30(1):7-8

Gupta V, Yayla A, Sikdar A, Cha M-S (2012) Institutional environment for entrepreneurship: evidence from the developmental states of South Korea and United Arab Emirates. J Dev Entrep 17(3):12500131250021

Hall JC, Nikolaev B, Pullito JM, VanMetre BJ (2013) The effect of personal and economic freedom on entrepreneurial activity: evidence from a new state level freedom index. Am J Entrep 6(1):88-103

Hayton J, Cacciotti (2014) Is there an entrepreneurial culture? A review of empirical research, Research Paper $\mathrm{N}^{\circ} 16$, Enterprise Research Centre (ERC) www.enterpriseresearch.ac.uk

Hofstede G (1991) Culture and organizations: software of the mind. McGraw-Hill, London

Kirzner I (1973) Competition and entrepreneurship. University of Chicago Press, Chicago

Kostova T (1997) Country institutional profiles: concept and measurement. Acad Manag Proc 1:180-184

Laeven L, Valencia F (2013) Systemic banking crises database. IMF Econ Rev 61(2):225-270

Levie J, Autio E (2008) A theoretical grounding and test of the GEM model. Small Bus Econ 31:235-263

Mandić D, Borović Z, Jovićević M (2017) Economic freedom and entrepreneurial activity: evidence from EU 11 countries. Economics 5(2):11-17

McMullen J, Bagby D, Palich L (2008) Economic freedom and the motivation to engage in entrepreneurial action. Entrep Theory Pract 32(5):875-895

Meek W, Pacheco D, York J (2010) The impact of social norms on entrepreneurial action: evidence from environmental entrepreneurship context. J Bus Ventur 25:493-509

Năstase C, Kajanus M (2010) The impact of the global crisis on SME and entrepreneurship behavior Romania and Finland cases. Amfiteatru Econ XII(27):751-762

North D (1990) Institutions, institutional change, and economic performance. Cambridge University Press, New York 
Papaoikonomon E, Segarra P, Lee X (2012) Entrepreneurship in the context of crisis: identifying barriers and proposing strategies. Int Adv Econ Res 18:111-119

Parker S, van Praag C (2010) Group status and entrepreneurship. J Econ Manag Strateg 19(4):919-945

Pinho JC, Thompson D (2017) Institutional-driven dimensions and the capacity to start a business. Int Mark Rev 34(6):787-813

Raza A, Muffatto M, \& Saeed S (2019) The influence of formal institutions on the relationship between entrepreneurial readiness and entrepreneurial behaviour: A cross-country analysis. J Small Bus Enterp Dev 26(1):133-157

Reyes G, Moslares C (2010) La unión Europea en crisis: 2008-2009. Rev Latinoam Econ 41(161):13-39

Reynolds P, Bosma N, Autio E, Hunt S, De Bono N, Servais I, Lopez-Garcia P, Chin N (2005) Global entrepreneurship monitor: data collection and implementation 1998-2003. Small Bus Econ 24(3):205-231

Riaz S (2009) The global financial crisis: an institutional theory analysis. Crit Perspect Int Bus 5(1/2):26-35

Sambharya R, Musteen M (2014) Institutional environment and entrepreneurship: An empirical study across countries. J Int Entrepreneurship 12:314-330

Sarasvathy S, Dew N, Velamuri S, Vankataraman S (2010) Three views of entrepreneurial opportunity. In: Acs ZJ, Audretsch DB (eds) Handbook of Entrepreneurial Research, 2nd edn. Kluwer, Boston, pp 77-96

Scott WR (1995) Institutions and organizations. Sage, Newbury Park

Scott WR (2014) Institutions and organizations: ideas, interests, and identities, 4rd edn. Sage Publications, Thousand Oaks

Shane S, Venkataraman S (2000) The promise of entrepreneurship as a field of research. Acad Manag Rev 25(1):217-226

Simón-Moya V, Revuelto-Taboada L, Ribeiro-Soriano D (2016) Influence of economic crisis on new SME survival: reality or fiction? Entrep Reg Dev 28(1-2):157-176

Sørensen J, Sharkey A (2014) Entrepreneurship as a mobility process. Am Sociol Rev 79(2):328-349

Stenholm P, Acs W, R. (2013) Exploring country-level institutional arrangements on the rate and type of entrepreneurial activity. J Bus Ventur 28:176-193

Urbano D, Alvarez C (2014) Institutional dimensions and entrepreneurial activity: an international study. Small Bus Econ 42:703-716

Urbano D, Aparício S, Audretsch D (2019) Twenty-five years of research on institutions, entrepreneurship, and economic growth: what has been learned? Small Bus Econ 53:21-49

Valdez M, Richardson J (2013) Institutional determinants of macro-level entrepreneurship. Enterp Theory Pract 37(5):983-1247

Welter F, Smallbone D (2011) Institutional perspectives on entrepreneurial behavior in challenging environments. J Small Bus Manag 49(1):107-125

Williams N, Vorley T (2015) The impact of institutional change on entrepreneurship in a crisis-hit economy: The case of Greece, Entrepreneurship Reg Dev 27(1-2):28-49

Wood M, McKinley W (2010) The production of entrepreneurial opportunity: a constructivist perspective. Strateg Entrep J 4(1):66-68

Publisher's note Springer Nature remains neutral with regard to jurisdictional claims in published maps and institutional affiliations. 